\title{
The Sleep-Modulating Peptide Cortistatin Augments the h-Current in Hippocampal Neurons
}

\author{
Paul Schweitzer, Samuel G. Madamba, and George R. Siggins \\ Department of Neuropharmacology, The Scripps Research Institute, La Jolla, California 92037
}

\begin{abstract}
Cortistatin (CST) is a sleep-modulating peptide found exclusively in the brain. Although CST is closely related to somatostatin (SST) and binds to SST receptors, CST has effects on sleep and neuronal activity in cortex and hippocampus that differ from SST. To uncover the cellular mechanisms affected by CST, we studied the electrophysiological postsynaptic effects of CST and assessed its interaction with SST on hippocampal CA1 pyramidal neurons. CST altered intrinsic membrane properties and occluded SST effects, indicating that both peptides similarly augment the sustained $\mathrm{K}^{+} \mathrm{M}$ - and leak-currents $\left(I_{\mathrm{M}}\right.$ and $\left.I_{\mathrm{K}(\mathrm{L})}\right)$. In the presence of SST, however, CST elicited an additional inwardly rectifying component in the hyperpolarized range. This effect was unaffected by barium, used to block $\mathrm{K}^{+}$currents, but was completely prevented by the selective h-current $\left(I_{\mathrm{h}}\right)$ blocker ZD7288. CST, but not SST, selectively increased $I_{\mathrm{h}}$ in a concentrationdependent manner by augmenting its maximum conductance. CST did not shift the $I_{\mathrm{h}}$ activation curve, and the peptide effect was unaffected by a membrane-permeable analog of cAMP. We conclude that CST and SST similarly increase $\mathrm{K}^{+}$conductances in hippocampal neurons, most likely by activating SST receptors. However, CST additionally augments $I_{\mathrm{h}}$, a voltage-dependent current that plays a key role in the modulation of synaptic integration and regulates oscillatory activity. Our results indicate that CST targets a specific conductance unaffected by SST to modulate cellular mechanisms implicated in sleep regulation.
\end{abstract}

Key words: somatostatin; M-current; potassium current; cation current; hippocampus; slice

\section{Introduction}

Cortistatin (CST) is a recently discovered peptide closely related to somatostatin (SST). Whereas SST is present in brain, gut, and pancreas, CST is found only in the brain, principally in cortical and hippocampal interneurons (De Lecea et al., 1996). CST and SST are the products of different genes, and fewer than half of the CST-expressing neurons also contain SST (De Lecea et al., 1997). CST binds to all five known SST receptors with high affinity (Csaba and Dournaud, 2001) and produces physiological effects similar to those of SST. Thus, the peptides depress hippocampal activity in vitro and in vivo (De Lecea et al., 1996), augment $\mathrm{K}^{+}$ conductances in hippocampus and locus ceruleus (De Lecea et al., 1996; Connor et al., 1997), depress the glutamate response in hypothalamic neurons (Vasilaki et al., 1998), and exhibit anticonvulsive properties (Braun et al., 1998). However, CST also elicits physiological effects distinct or opposite to those of SST and is believed to be an endogenous regulator of sleep: CST induces slow-wave sleep (SST increases rapid eye movement sleep) and prevents the excitatory effects of acetylcholine (SST enhances such effects) (De Lecea et al., 1996). These differences are likely to arise from modulation of distinctive cellular mechanisms, but little is known about the neuronal site of action of CST. Such mechanisms need to be characterized to further understand the

\footnotetext{
Received June 4, 2003; revised 0ct. 8, 2003; accepted 0ct. 9, 2003.

This work was supported by National Institute of Health Grants DA 13658 and MH 44346. We thank Drs. Floyd Bloom and Luis de Lecea for comments on this manuscript.

Correspondence should be addressed to Dr. P. Schweitzer, The Scripps Research Institute, Department of Neuropharmacology, CVN 12, 10550 North Torrey Pines Road, La Jolla, CA 92037. E-mail: pschweitzer@scripps.edu. Copyright $\odot 2003$ Society for Neuroscience $\quad 0270-6474 / 03 / 2310884-08 \$ 15.00 / 0$
}

role and function of CST and how it differentially modulates sleep physiology.

Brain rhythms that affect behavioral states such as sleep are shaped in part by sustained conductances that support the electrical resonance and oscillatory activity of neuronal networks (Pape, 1996; Hutcheon and Yarom, 2000). In hippocampus, in which CST is abundantly expressed, pyramidal neurons are key players in the modulation of network oscillatory rhythms. These principal cells are under the tonic control of sustained conductances active at or near resting potential, such as the $\mathrm{K}^{+} I_{\mathrm{M}}$ and $I_{\mathrm{K}(\mathrm{L})}$ and the cation $I_{\mathrm{h}}$ (Halliwell and Adams, 1982; Brown et al., 1990). The voltage-dependent inward rectifier $I_{\mathrm{h}}$ (previously termed $I_{\mathrm{Q}}$ ) and outward rectifier $I_{\mathrm{M}}$ participate in theta resonance (Hu et al., 2002). $I_{\mathrm{h}}$ is also implicated in hippocampal gamma oscillations and synaptic integrative mechanisms (Magee, 2000; Fisahn et al., 2002) and plays a key role in the generation and control of rhythmic activity, especially thalamic oscillations associated with sleep patterns (Pape, 1996; Luthi and McCormick, 1998). SST inhibits CA1 pyramidal neurons via augmentation of $I_{\mathrm{M}}$ and $I_{\mathrm{K}(\mathrm{L})}$ but does not affect $I_{\mathrm{h}}$ (Moore et al., 1988; Schweitzer et al., 1998), and CST also augments $I_{\mathrm{M}}$ (De Lecea et al., 1996). The aim of this study was to uncover cellular mechanisms specific to CST to better delineate its distinct physiological effects. We investigated the postsynaptic effects of CST in parallel with those of SST and found that CST specifically augments $I_{\mathrm{h}}$, pointing to a CST site of action unaffected by SST.

\section{Materials and Methods}

Slice preparation. We used standard intracellular recording techniques in rat hippocampal slices as described previously (Schweitzer et al., 1993). 
In brief, transverse hippocampal slices (taken from male Sprague Dawley rats of 100-170 gm) $350 \mu \mathrm{m}$ thick were cut on a brain slicer and incubated in gassed $\left(95 \% \mathrm{O}_{2}, 5 \% \mathrm{CO}_{2}\right)$ artificial CSF (ACSF) of the following composition (in mM): $130 \mathrm{NaCl}, 3.5 \mathrm{KCl}, 1.25 \mathrm{NaH}_{2} \mathrm{PO}_{4}, 1.5 \mathrm{MgSO}_{4}, 2.0$ $\mathrm{CaCl}_{2}, 24 \mathrm{NaHCO}_{3}$, and 10 glucose. We added other ions and agents to this ACSF. Slices were completely submerged and continuously superfused with warm $\left(31^{\circ} \mathrm{C}\right)$ ACSF. Methods of superfusion, voltage-clamp recording, drug administration, and data analysis were as described previously (Schweitzer et al., 1993). We purchased CST and SST from Peninsula Laboratories (Belmont, CA), ZD7288 from Tocris Cookson (Ballwin, MO), and all other chemicals from Sigma (St. Louis, MO).

Electrophysiological recordings. We performed intracellular voltageclamp studies with an Axoclamp 2A amplifier (Axon Instruments, Foster City, CA), using sharp glass micropipettes filled with $3 \mathrm{~m} \mathrm{KCl}$ (average resistance of $68 \pm 2 \mathrm{M} \Omega$ ) to penetrate CA1 pyramidal neurons. In discontinuous single-electrode voltage-clamp mode, the switching frequency between current injection and voltage sampling was $3-4 \mathrm{kHz}$. Current and voltage records were filtered at $0.3 \mathrm{kHz}$ and acquired by digital-to-analog sampling and acquisition software (pClamp; Axon Instruments) and then fitted and measured with pClamp software. Graphs were constructed and fit using Origin software (Microcal Software, Northampton, MA). Values are presented as mean \pm SEM. The various problems (for example, space clamping) associated with voltage clamping of neurons with extended processes have been discussed previously (Halliwell and Adams, 1982; Johnston and Brown, 1983) but should be minimized by the study of relative conductance changes with superfusion of drugs to equilibrium conditions.

We generated current-voltage $(I-V)$ curves by holding neurons at approximately $-61 \mathrm{mV}$ and applying hyperpolarizing and depolarizing voltage steps ( $1.5 \mathrm{sec}$ duration, $7 \mathrm{sec}$ apart). Steady-state currents were measured at the end of the voltage steps. To assess $I_{\mathrm{h}}$, neurons were held at approximately $-61 \mathrm{mV}$ and hyperpolarized in $14 \mathrm{mV}$ increments (1.5 sec duration, $7 \mathrm{sec}$ apart). We quantified $I_{\mathrm{h}}$ as the difference between the peak current of the relaxation (best fit using pClamp) observed at onset of hyperpolarizing voltage steps (after the capacitance artifact, no extrapolation) and the current measured at the end of the voltage step. To determine $I_{\mathrm{h}}$ activation curves, we applied a two-step protocol in the presence of $1 \mathrm{mM} \mathrm{Ba}^{2+}$. Neurons were held at approximately $-44 \mathrm{mV}$ and hyperpolarized in $-11 \mathrm{mV}$ increments (first step or prepulse) and then further stepped to a final potential of approximately $-143 \mathrm{mV}$ (second step). To assess $I_{\mathrm{M}}$, neurons were held at approximately $-45 \mathrm{mV}$ and hyperpolarized in $5 \mathrm{mV}$ increments ( $1 \mathrm{sec}$ duration, $5 \mathrm{sec}$ apart). We quantified the $I_{\mathrm{M}}$ relaxation in a manner similar to the $I_{\mathrm{h}}$ relaxation.

\section{Results}

We recorded intracellularly from 80 CA1 hippocampal pyramidal neurons that had a resting membrane potential (RMP) of $-69 \pm 0.2 \mathrm{mV}$ (mean $\pm \mathrm{SEM})$. The mean action potential amplitude was $105 \pm 1 \mathrm{mV}$, and mean input resistance was $74 \pm 2$ $\mathrm{M} \Omega$. We added tetrodotoxin $(1 \mu \mathrm{M})$ in the superfusate to block synaptic transmission throughout all experiments.

\section{Cortistatin affects several postsynaptic conductances and occludes somatostatin effects}

Addition of $1 \mu \mathrm{M}$ CST to the superfusate elicited a slowly developing outward current associated with a conductance increase in 22 of 26 neurons (Fig. 1A). During washout of the peptide, current values went back to preapplication level. Thus, CST had a reversible postsynaptic effect to inhibit pyramidal neurons around resting potential. We generated $I-V$ relationships to study the effects of CST on steady-state membrane properties at depolarized and hyperpolarized potentials. CST elicited a clear effect across the whole voltage range tested, with an outward current at depolarized potentials and an inward current at hyperpolarized potentials (Fig. $1 \mathrm{~B}$ ). All current values recovered to near control values on washout. Subtraction of control values from those observed in the presence of CST revealed the net
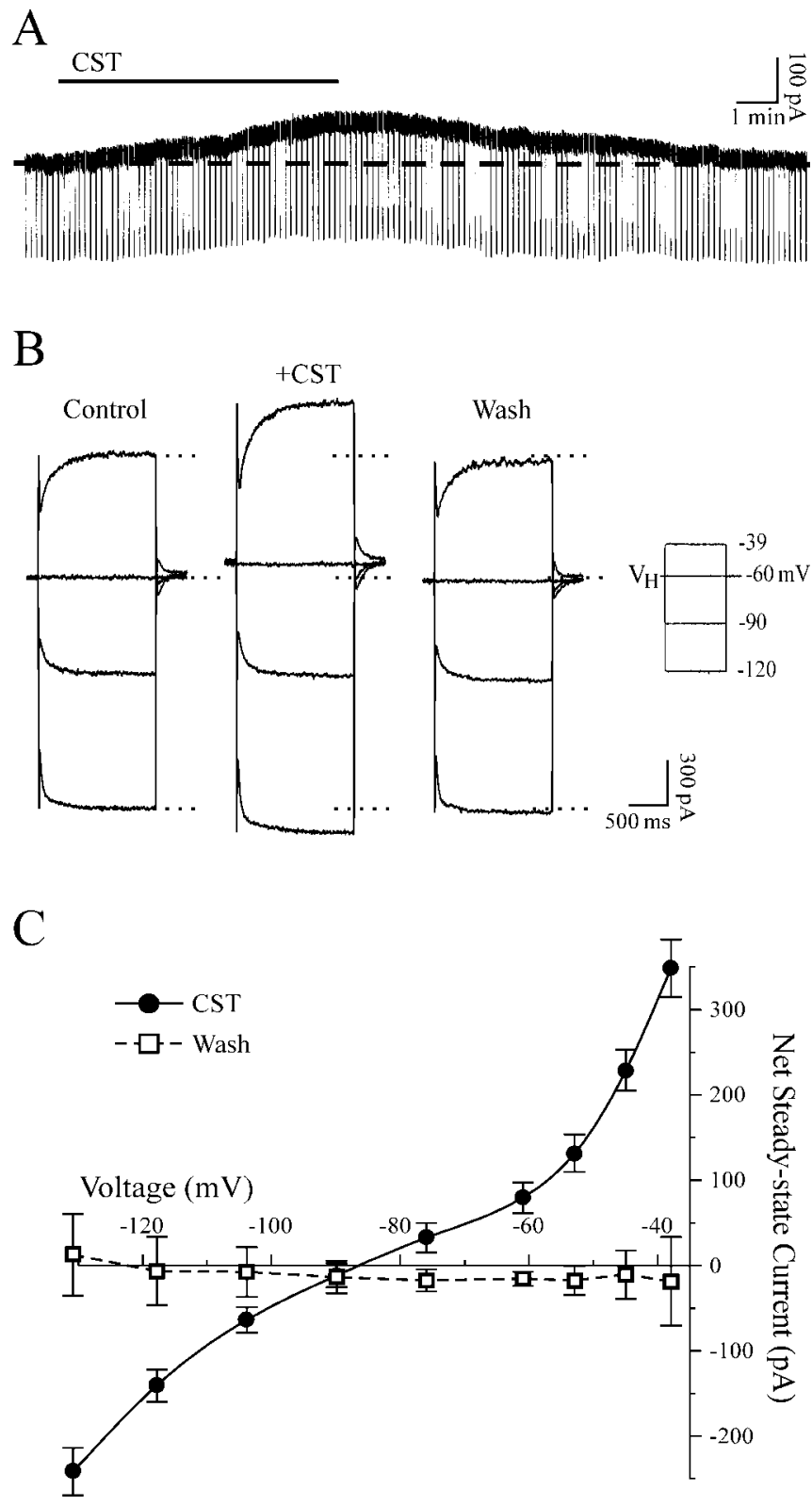

Figure 1. Cortistatin postsynaptically inhibits $C A 1$ pyramidal neurons. $A$, Continuous current recording of a neuron held at $-65 \mathrm{mV}$, near its RMP of $-69 \mathrm{mV}$. Superfusion of $1 \mu \mathrm{M}$ CST (bar, adjusted to effect onset) elicited a slowly developing outward current associated with an increased input conductance. During washout, current values returned to control level (dashed line). Downward deflections are currents elicited by $10 \mathrm{mV}$ hyperpolarizing voltage steps. $B$, Selected current traces of a representative neuron held at $-60 \mathrm{mV}$ and subjected to three different voltage steps sequentially applied and superimposed at each condition (voltage protocol on the right). CST (1 $\mu \mathrm{M}$ ) elicited an outward steady-state current at depolarized potentials and an inward current at hyperpolarized potentials. Dotted lines indicate control condition levels; RMP was $-68 \mathrm{mV}$. C, Average of the net steady-state currents (subtracted from control) from 15 neurons. The CST effect showed outward rectification at potentials positive to $-70 \mathrm{mV}$ and inward rectification at potentials negative to $-80 \mathrm{mV}$. The reversal potential of $-86 \mathrm{mV}$ suggested that CST did not solely affect $\mathrm{K}^{+}$conductances.

current elicited by the peptide $(n=15)$ (Fig. $1 C)$. The reversal potential for the CST effect was $-86 \pm 2 \mathrm{mV}$, and the outward component $(348 \pm 34 \mathrm{pA}$ at $-38 \mathrm{mV})$ was outwardly rectifying, whereas the inward component $(-242 \pm 28 \mathrm{pA}$ at $-131 \mathrm{mV})$ appeared to rectify inwardly. The reversal potential suggested that CST augmented $\mathrm{K}^{+}$conductances to inhibit pyramidal neurons. However, the theoretical value of the $\mathrm{K}^{+}$equilibrium po- 


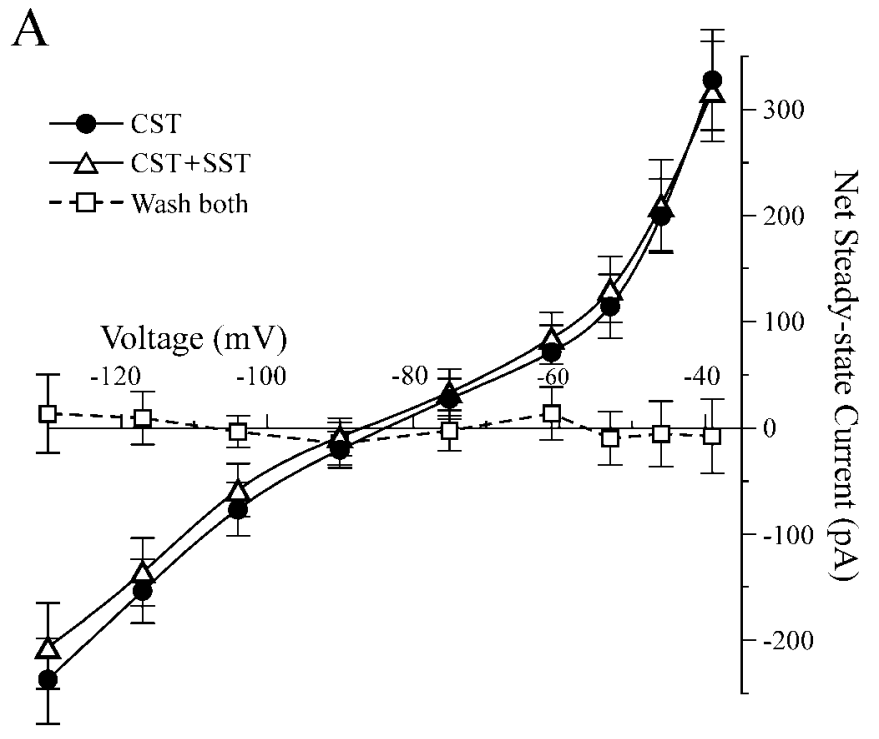

B

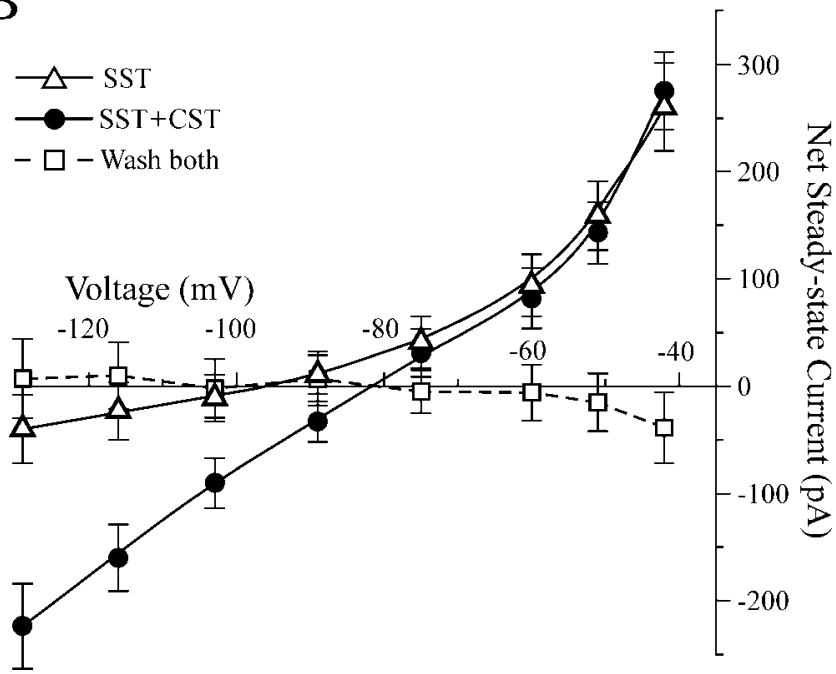

Figure 2. Cortistatin elicits an additional effect at hyperpolarized potentials. A, Net steadystate currents obtained from eight neurons exposed to $1 \mu \mathrm{m}$ CST followed by $1 \mu \mathrm{m}$ SST in the continued presence of CST. SST did not elicit an additional effect after the CST response was established. $B$, The reverse sequence of application (SST followed by CST) revealed that CST elicited an additional effect at potentials negative to $-50 \mathrm{mV}(n=7)$. This inward component was voltage dependent and increased with hyperpolarization.

tential calculated using the Nernst equation was $-98 \mathrm{mV}$ in our experimental conditions ( $3.5 \mathrm{~mm}$ extracellular $\mathrm{K}^{+}$and assuming $150 \mathrm{~mm}$ intracellular $\mathrm{K}^{+}$). This shift in the reversal potential suggested that CST, unlike SST, affected another conductance not carried solely by $\mathrm{K}^{+}$.

SST is known to augment two non-inactivating $\mathrm{K}^{+}$conductances in pyramidal neurons, $I_{\mathrm{M}}$ and $I_{\mathrm{K}(\mathrm{L})}$. We investigated the interaction of CST and SST by performing sequential applications of the two peptides. In this neuronal sample $(n=8), 1 \mu \mathrm{M}$ CST alone elicited a steady-state current reversing at $-84 \pm 3 \mathrm{mV}$ (Fig. 2A). After the CST response reached equilibrium, we added $1 \mu \mathrm{M}$ SST in the continued presence of CST. We did not observe additional alterations of the $I-V$ profile during superfusion of SST (Fig. 2A). Because the presence of CST in the superfusate completely occluded the response to SST, we conclude that CST augments $I_{\mathrm{M}}$ and $I_{\mathrm{K}(\mathrm{L})}$ to the same extent as SST.

\section{Cortistatin elicits an additional effect not observed} with somatostatin

The CST response at hyperpolarized potentials showed rectification, a feature not observed in previous work with SST (Schweitzer et al., 1998). We therefore investigated the possibility that CST had a specific effect not attributable to activation of SST receptors. For this purpose, we performed interaction experiments by adding CST to slices preexposed to SST to reveal an additional response. SST alone induced an outward current reversing at $-96 \pm 4 \mathrm{mV}(n=7)$ (Fig. $2 B)$, near the theoretical equilibrium potential of $-98 \mathrm{mV}$ for $\mathrm{K}^{+}$ions. The response showed outward rectification at potentials positive to $-70 \mathrm{mV}$ and appeared linear in the hyperpolarized range, in accord with previous studies demonstrating augmentation of the voltagedependent $I_{\mathrm{M}}$ and the voltage-independent $I_{\mathrm{K}(\mathrm{L})}$ by SST. Addition of CST in the continued presence of SST elicited an additional effect at potentials negative to $-60 \mathrm{mV}(n=7)$ (Fig. $2 B$ ). CST concomitantly shifted the reversal potential of the overall response from $-96 \pm 4$ to $-82 \pm 3 \mathrm{mV}$, revealing an effect on an additional sustained conductance.

To further characterize the CST-specific component, we subtracted the response obtained with CST from the response obtained with SST alone to isolate the net additional current elicited by CST $(n=7)$ (Fig. $3 A$ ). We established that the CST component was voltage dependent with a threshold of activation at -54 $\mathrm{mV}$; it increased with hyperpolarization and exhibited inward rectification. From these results, we calculated the conductance increase elicited by CST, $\Delta G_{\mathrm{CST}}$, by dividing the CST-specific current by the driving force to its reversal potential $(n=7)$ (Fig. $3 B$ ). The conductance $\Delta G_{\mathrm{CST}}$ rapidly increased between -60 and $-120 \mathrm{mV}$ and yielded a maximum of $2.50 \mathrm{nS}$ at $-140 \mathrm{mV}$. The resulting half-maximum activation potential was $-94 \mathrm{mV}$.

\section{Cortistatin increases the $\mathrm{h}$-current}

The features displayed by the CST-specific component closely resembled the properties of the hyperpolarization-activated $I_{\mathrm{h}}$. This current is best observed in CA1 pyramidal neurons as a slow relaxation that develops during hyperpolarization, usually from a holding potential negative to $-60 \mathrm{mV}$ to avoid contamination by the $I_{M}$ relaxation. We held neurons at $-61 \pm 1 \mathrm{mV}(n=38)$ and delivered five hyperpolarizing voltage steps $(-14 \mathrm{mV}$ increments) to study the modulation of $I_{\mathrm{h}}$ by the peptides. The application of SST elicited an outward steady-state current at holding potential but did not affect the amplitude of $I_{\mathrm{h}}$. Superfusion of CST in the continued presence of SST, however, augmented $I_{\mathrm{h}}$ and concomitantly elicited an inward steady-state current at hyperpolarized potentials (Fig. 4A). On average, the $I_{\mathrm{h}}$ amplitude remained at $102 \pm 2 \%$ of control during superfusion of SST, whereas subsequent addition of CST augmented $I_{\mathrm{h}}$ to $125 \pm 5 \%$ of control $(n=6)$ (Fig. $4 B$ ). The augmenting action of CST on $I_{\mathrm{h}}$ was comparable at all potentials, ranging from $123 \pm 5 \%$ of control at $-90 \mathrm{mV}$ to $127 \pm 4 \%$ at $-130 \mathrm{mV}$. The CST-induced increase of $I_{\mathrm{h}}$ was not dependent on the presence of SST. In neurons exposed to $1 \mu \mathrm{M}$ CST alone, the peptide increased $I_{\mathrm{h}}$ to $126 \pm 3 \%$ of control (range of $125 \pm 3$ to $128 \pm 3 \%$; $n=17$ ), with recovery to $96 \pm 2 \%$ of control during washout. The augmentation of $I_{\mathrm{h}}$ by CST was concentration dependent. Superfusion of 50 nM CST had no effect, but a small $I_{\mathrm{h}}$ increase was detected at 100 $\mathrm{nM}$, and the maximum effect was obtained with $1 \mu \mathrm{M}$. Concentration-response analysis of CST (Fig. 4D) gave a sigmoidal (logistic) fit of the data points, yielding an apparent $\mathrm{EC}_{50}$ of $300 \pm 51 \mathrm{~nm}$.

The augmentation of $I_{\mathrm{h}}$ by CST was not altered by a subsequent application of SST. In seven cells, CST increased $I_{\mathrm{h}}$ to 
A

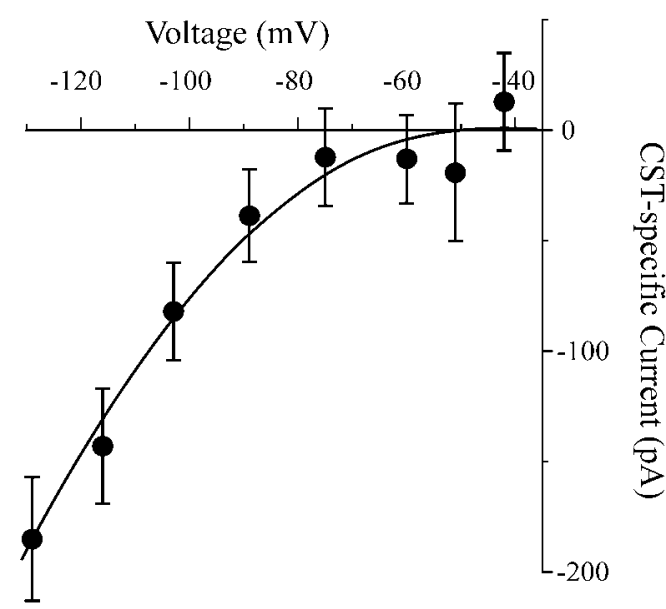

B

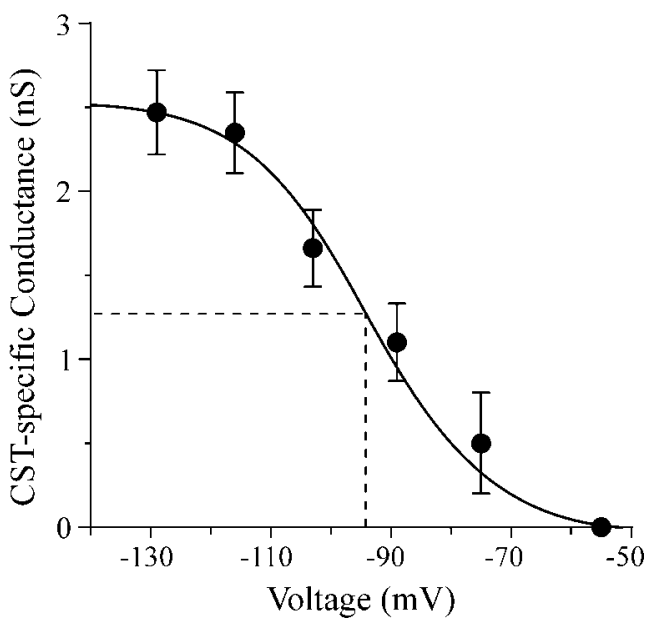

Figure 3. Cortistatin-specific current and conductance. A, CST-specific component isolated by subtracting the currents obtained in SST plus CST from those obtained in SST alone (as in Fig. $2 B ; n=7$ ). (ST elicited an inwardly rectifying current that activated at $-54 \mathrm{mV}$. Curve was obtained by polynomial fit. $B$, The CST-induced conductance increase, $\Delta G_{C S T}$, was calculated as $I_{\text {CST }} /\left(V-V_{\text {rev }}\right)$, where $I_{\text {CST }}$ is the CST-induced current, and $V-V_{\text {rev }}$ is the driving force $(V$ indicates command potential, and $V_{\text {rev }}$ indicates reversal potential). The $\Delta G_{\text {CST }}$ appeared to reach a maximum at $-140 \mathrm{mV}$ and yielded a half-maximum activation potential of $-94 \mathrm{mV}$ (dashed line).

$124 \pm 5 \%$ of control, and $I_{\mathrm{h}}$ remained increased at $122 \pm 5 \%$ during addition of SST (data not shown). To rule out misinterpretations that could arise from contamination of the $I_{\mathrm{h}}$ relaxation by the $I_{\mathrm{M}}$ relaxation, we also monitored the effect of the peptides on $I_{\mathrm{M}}$. Neurons were held at $-45 \pm 1 \mathrm{mV}$ and subjected to five hyperpolarizing voltage steps ( $-5 \mathrm{mV}$ increments). There was no additional effect of CST on $I_{M}$ in the presence of SST. The $I_{\mathrm{M}}$ was augmented to $153 \pm 5 \%$ of control during superfusion of SST alone and remained increased at $155 \pm 6 \%$ during subsequent addition of CST $(n=7)$ (Fig. $4 C)$.

\section{Characterization of the cortistatin effect on $I_{h}$}

To eliminate the involvement of $I_{\mathrm{M}}$ and $I_{\mathrm{K}(\mathrm{L})}$ and further characterize the CST-specific effect, we conducted experiments with 1 mM barium $\left(\mathrm{Ba}^{2+}\right)$ in the superfusate to block $\mathrm{K}^{+}$currents. In slices pretreated with $\mathrm{Ba}^{2+}$, CST still elicited an inward steadystate current at hyperpolarized potentials but had no effect in the depolarized range (Fig. 5A). Construction of $I-V$ relationships
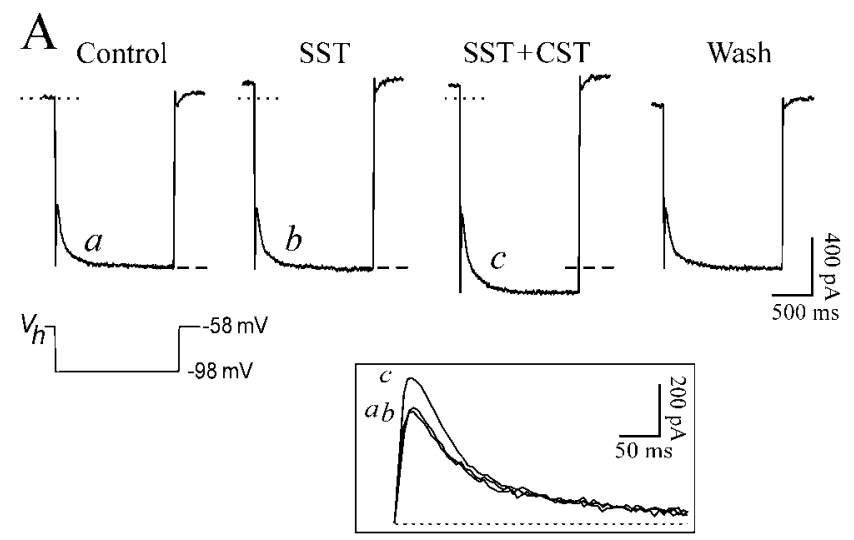

$\mathrm{B}$

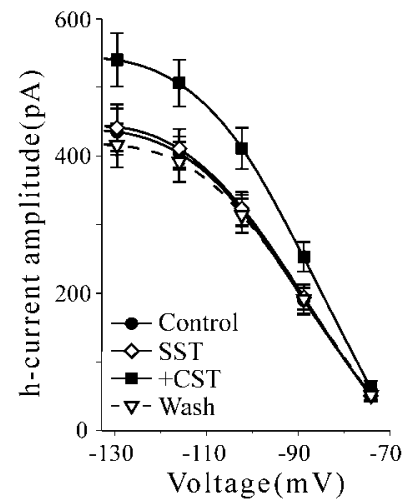

C

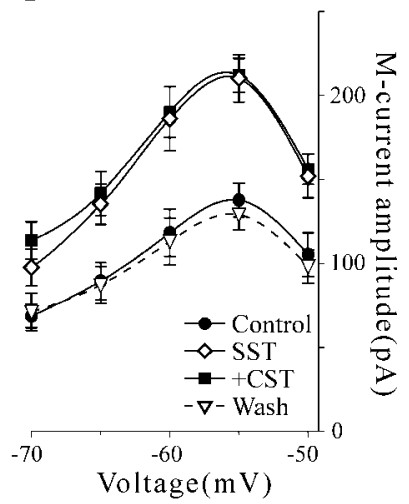

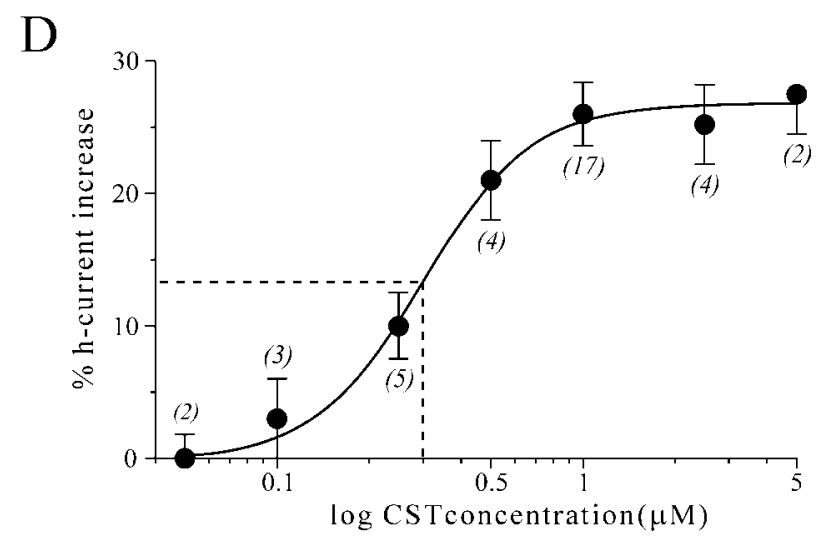

Figure 4. Cortistatin increases $I_{h}$. $A$, Neuron stepped from -58 to $-98 \mathrm{mV}$. SST elicited an outward current at $-58 \mathrm{mV}$ (dotted line is control level) but had no effect at $-98 \mathrm{mV}$ (dashed line), the reversal potential for $\mathrm{K}^{+}$. The addition of CST had no effect at $-58 \mathrm{mV}$ (threshold of $I_{\mathrm{h}}$ activation) but induced an inward current concomitant with an $I_{\mathrm{h}}$ augmentation at $-98 \mathrm{mV}$. The bottom inset shows the $I_{\mathrm{h}}$ relaxations (identified with letters) magnified and superimposed. RMP was $-69 \mathrm{mV}$. B, Plot average of the $I_{\mathrm{h}}$ relaxation amplitude $(n=6$; curve was obtained by polynomial fit). SST alone did not affect $I_{h}$, but CST applied in the presence of SST increased $I_{\mathrm{h}}$ at all potentials. C, Plot average of the $I_{\mathrm{M}}$ relaxation amplitude $(n=6$; polynomial fit). SST augmented $I_{M}$, and addition of CST did not further alter $I_{M} \cdot D$, Concentration-response curve of the $I_{h}$ relaxation augmentation by $C S T$. The threshold response was below $0.1 \mu \mathrm{M}$, and the maximal effect was obtained with $1 \mu \mathrm{m}$ to augment $I_{\mathrm{h}}$ by $26 \%$. The apparent $\mathrm{EC}_{50}$ was $0.30 \pm 0.05 \mu \mathrm{m}$ (dashed line). Curve was obtained by sigmoidal (logistic) fit; number of cells at each concentration are in parentheses.

and analysis of the net effect confirmed that CST elicited a voltage-dependent component that activated at $-52 \mathrm{mV}$ and rectified inwardly $(n=8)$ (Fig. $5 B)$, properties similar to those seen in absence of $\mathrm{Ba}^{2+}$. The inward current was concomitant 
A

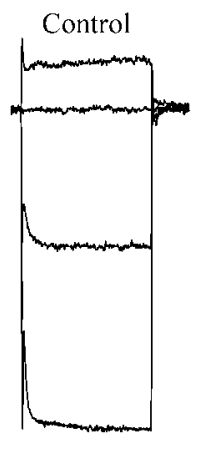

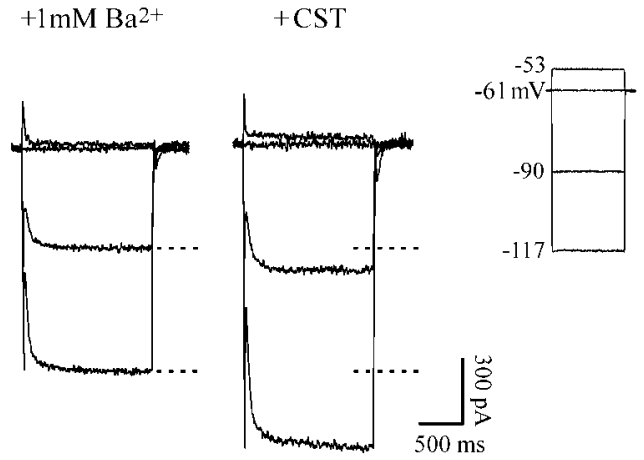
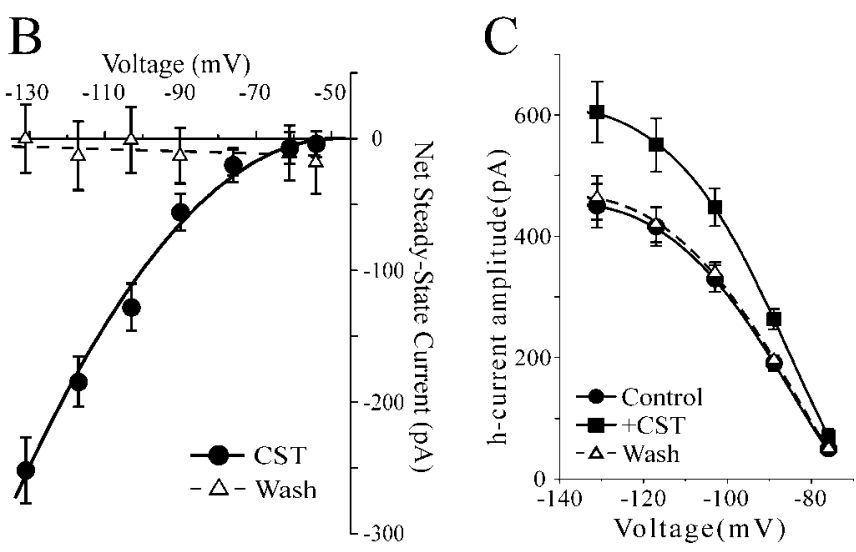

Figure 5. Characterization of the cortistatin effect in barium. $A$, Neuron was held at $-61 \mathrm{mV}$ and subjected to three different voltage steps (protocol at right). Application of $1 \mathrm{~mm} \mathrm{Ba}^{2+}$ blocked $\mathrm{K}^{+}$currents and decreased input conductance. Addition of $1 \mu \mathrm{m}$ CST elicited an inward steady-state current at hyperpolarized potentials (dashed line is pre-peptide level) but had no effect at depolarized potentials. RMP was $-70 \mathrm{mV}$ before $\mathrm{Ba}^{2+}$. $B$, Net steady-state currents obtained from seven neurons exposed to CST in presence of $\mathrm{Ba}^{2+}$. CST elicited a voltagedependent inwardly rectifying current that activated at $-52 \mathrm{mV}$. C, Averaged $I_{\mathrm{h}}$ amplitudes in 10 cells exposed to CST in the presence of $\mathrm{Ba}^{2+}$. The peptide increased $I_{\mathrm{h}}$ to $135 \%$ of control.

with an augmentation of $I_{\mathrm{h}}$ to $135 \pm 5 \%$ of control across all potentials (range of $132 \pm 4$ to $137 \pm 5 \% ; n=11$ ), with recovery to $98 \pm 4 \%$ of control values during washout (Fig. $5 C$ ). Both the inward steady-state component and the augmentation of $I_{\mathrm{h}}$ elicited by CST were larger by $\sim 10 \%$ in $\mathrm{Ba}^{2+}$, a result that we attribute to improved space-clamp conditions caused by blockade of $\mathrm{K}^{+}$currents. To fully attribute the additional CST effect to $I_{\mathrm{h}}$, we used the selective $I_{\mathrm{h}}$ blocker ZD7288 (BoSmith et al., 1993), an $\mathrm{IC}_{50}$ of $11 \mu \mathrm{M}$ obtained for CA1 neurons (Gasparini and DiFrancesco, 1997) in slices pretreated with $1 \mathrm{mM} \mathrm{Ba}^{2+}$. During addition of $100 \mu \mathrm{M}$ ZD7288, the h relaxation was blocked, although a small slow component remained $7 \pm 4 \%$ of preZD7288 value; $n=4$ ) (Fig. $6 A, B$ ). Subsequent addition of CST to the superfusate did not affect the remaining slow component and had only a just-measurable effect on steady-state current values, in sharp contrast to the large effect observed without ZD7288 (Fig. 6C).

To determine the characteristics of $I_{\mathrm{h}}$ activation, we constructed activation curves using a two-step voltage protocol: neurons were hyperpolarized to gradually increasing potentials (first step or prepulse) to partially activate $I_{\mathrm{h}}$ and then further hyperpolarized to a second potential that enabled full activation of the remaining $I_{\mathrm{h}}$ (Fig. 7A). The normalized amplitude of $I_{\mathrm{h}}\left(I_{\mathrm{h}} / I_{\mathrm{h}}\right.$ $\max$ ) was therefore inversely related to the degree of $I_{\mathrm{h}}$ activation

A

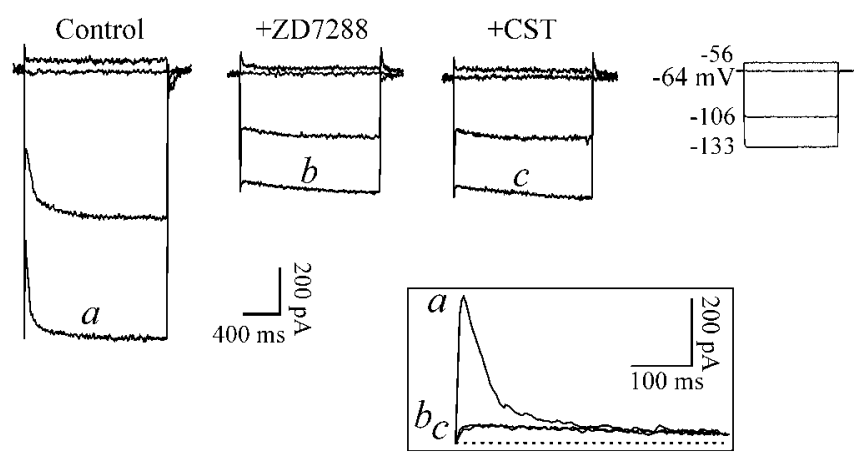

$\mathrm{B}$

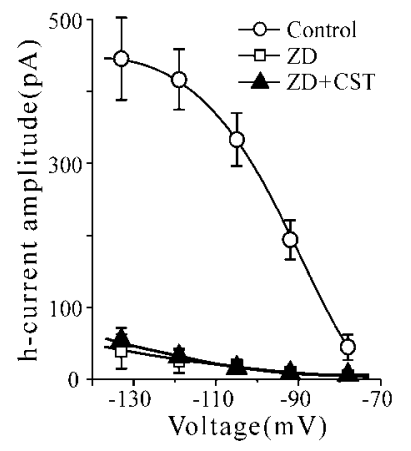

$\mathrm{C}$

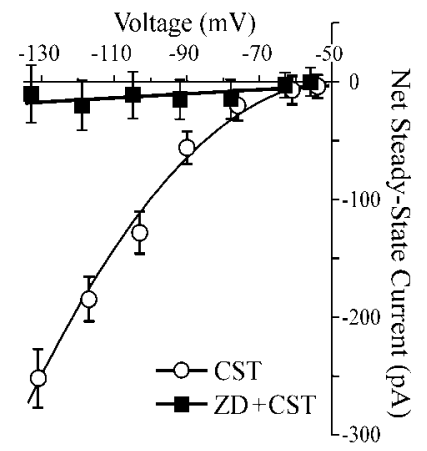

Figure 6. The $I_{\mathrm{h}}$ blocker ZD7288 prevents the CST effect. $A$, Neuron was bathed in $1 \mathrm{~mm}$ $\mathrm{Ba}^{2+}$, held at $-64 \mathrm{mV}$, and subjected to three different voltage steps (protocol at right). ZD7288 $(100 \mu \mathrm{M})$ decreased the input conductance and concomitantly blocked $I_{\mathrm{h}}$. Further addition of CST had no effect. The bottom inset shows $I_{\mathrm{h}}$ relaxations magnified and superimposed. RMP was $-71 \mathrm{mV}$ before $\mathrm{Ba}^{2+}$. $B$, Averaged $I_{\mathrm{h}}$ amplitude $\left(n=4 ; 1 \mathrm{mM} \mathrm{Ba}{ }^{2+}\right)$. ZD7288 obliterated $I_{h}$, and subsequent addition of CST had no effect. C, Net steady-state currents obtained from two neuronal samples exposed to CST in the absence or presence of ZD7288 $(n=7$ and 4, respectively; $1 \mathrm{~mm} \mathrm{Ba}{ }^{2+}$ ). With functional h-channels, (ST elicited a large voltagedependent effect. With $/ \mathrm{h}$ blocked by ZD7288, CST had a small nonspecific effect.

at the prepulse potential (Maccaferri et al., 1993). In the presence of $1 \mathrm{mM} \mathrm{Ba}^{2+}$, neurons were hyperpolarized in $-11 \mathrm{mV}$ increments (prepulse) from a holding potential of $-44 \pm 1 \mathrm{mV}$ to a final $-143 \pm 1 \mathrm{mV}$ (second step). CST elicited an inward steadystate current concomitant with an augmentation of $I_{\mathrm{h}}$ amplitude across the activation range, indicative of increased maximal conductance (Fig. $7 B$ ). The normalized $I_{\mathrm{h}}$ amplitude obtained at the second step was plotted against the prepulse potential, and the data were fitted with a Boltzmann function. The sigmoidal fit yielded a half-activation potential of $-95.6 \pm 1.0 \mathrm{mV}$ and slope of $10.4 \pm 0.8$ in control and a half-activation potential of $-94.1 \pm 1.1 \mathrm{mV}$ and slope of $10.6 \pm 1.0 \mathrm{in} \operatorname{CST}(n=5)$ (Fig. $7 C)$. Thus, the slopes were identical and the depolarizing shift in the activation curve was minimal $(1.5 \mathrm{mV})$. It thus appears that CST selectively and solely augments the maximal conductance of $I_{\mathrm{h}}$ in CA1 pyramidal neurons to elicit an inward steady-state current.

cAMP does not appear to participate in the cortistatin effect Most transmitters that modulate $I_{\mathrm{h}}$ do so by altering the level of cAMP. To investigate a role of the nucleotide in the effect of CST on $I_{\mathrm{h}}$, we used the two-step voltage protocol to study $I_{\mathrm{h}}$ activation in neurons exposed to the membrane-permeable analog 8-bromo-cAMP (8Br-cAMP). Superfusion of $1 \mathrm{mM} 8 \mathrm{Br}$-cAMP alone increased $I_{\mathrm{h}}$ to $111 \pm 4 \%$ of control at approximately mid- 


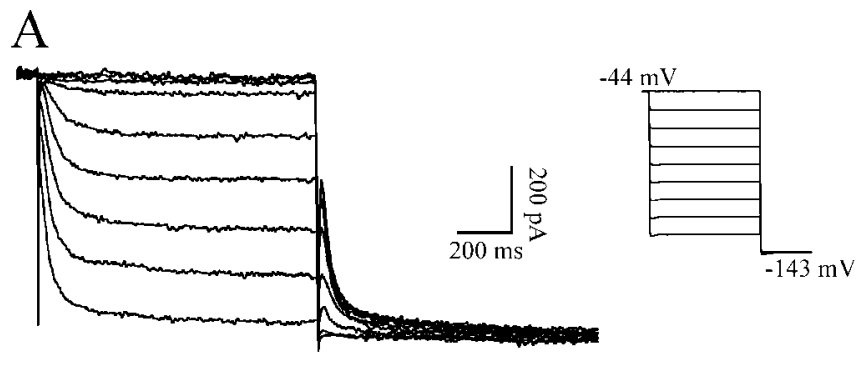

B
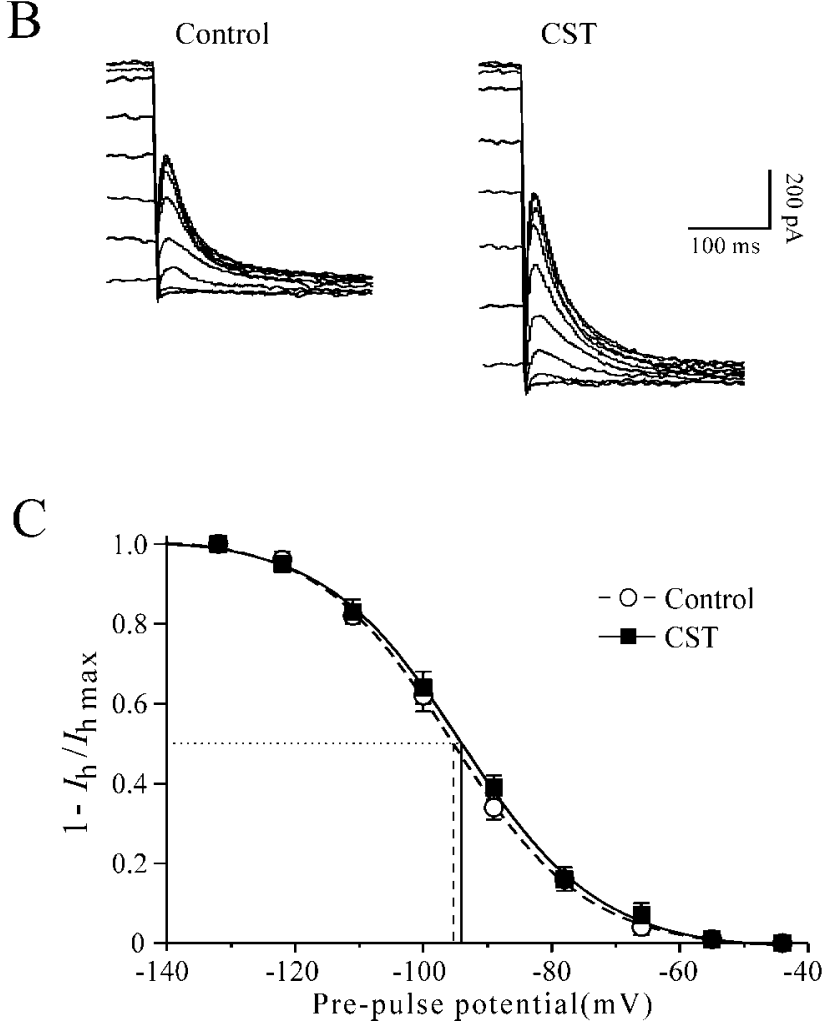

Figure 7. Cortistatin does not alter $I_{\mathrm{h}}$ activation curve. $A, A$ two-step protocol was used to study $I_{\mathrm{h}}$ activation. The prepulse (first step) was incremented by $-11 \mathrm{mV}$ from a holding potential of $-44 \mathrm{mV}$. From each prepulse potential, $I_{\mathrm{h}}$ was fully activated with a second step to $-143 \mathrm{mV}$. Current traces were leak corrected, $1 \mathrm{~mm} \mathrm{Ba}{ }^{2+}$ was used throughout, and RMP was $-70 \mathrm{mV}$ before $\mathrm{Ba}^{2+} . B$, Magnification of the current traces obtained at $-143 \mathrm{mV}$. CST elicited an inward steady-state current associated with $/ \mathrm{h}$ augmentation from all prepulse potentials. $C$, Averaged activation curves constructed from $/ \mathrm{h}$ amplitudes obtained at full activation potential (second step) relative to the prepulse potential $(n=5)$. The graph represents the difference to the maximal current amplitude after normalization $\left(1-I_{\mathrm{h}} / I_{\mathrm{h}} \max\right.$, at each condition). Data were fitted using a Boltzmann function. Cortistatin induced a minimal shift of $+1.5 \mathrm{mV}$ in the activation curve.

activation potential (prepulse from $-43 \pm 1$ to $-89 \pm 1 \mathrm{mV}$ ), but at the second step (from -89 to $-144 \pm 1 \mathrm{mV}$, activation of residual $\left.I_{\mathrm{h}}\right), I_{\mathrm{h}}$ amplitude was $93 \pm 3 \%$ of control $(n=6)$ (Fig. $8 A$ ). The sigmoidal fit of the normalized $I_{\mathrm{h}}$ amplitude obtained at the second step yielded a half-activation potential of $-95.4 \pm 1.3$ $\mathrm{mV}$ and slope of $10.9 \pm 1.2$ in control condition and a halfactivation potential of $-90.3 \pm 1.3 \mathrm{mV}$ and slope of $10.6 \pm 1.1 \mathrm{in}$ $8 \mathrm{Br}$-cAMP $(n=6)$ (Fig. $8 \mathrm{~B})$. Concomitantly, the maximal amplitude of $I_{\mathrm{h}}$ assessed with a single step from -43 to $-144 \mathrm{mV}$ (full activation at once) was $102 \pm 3 \%$ of control. Thus, $8 \mathrm{Br}$ cAMP shifted the $I_{\mathrm{h}}$ activation curve by $+5 \mathrm{mV}$ without affecting the maximal conductance of $I_{\mathrm{h}}$.

Subsequent addition of CST in the continued presence of $8 \mathrm{Br}$ -
A
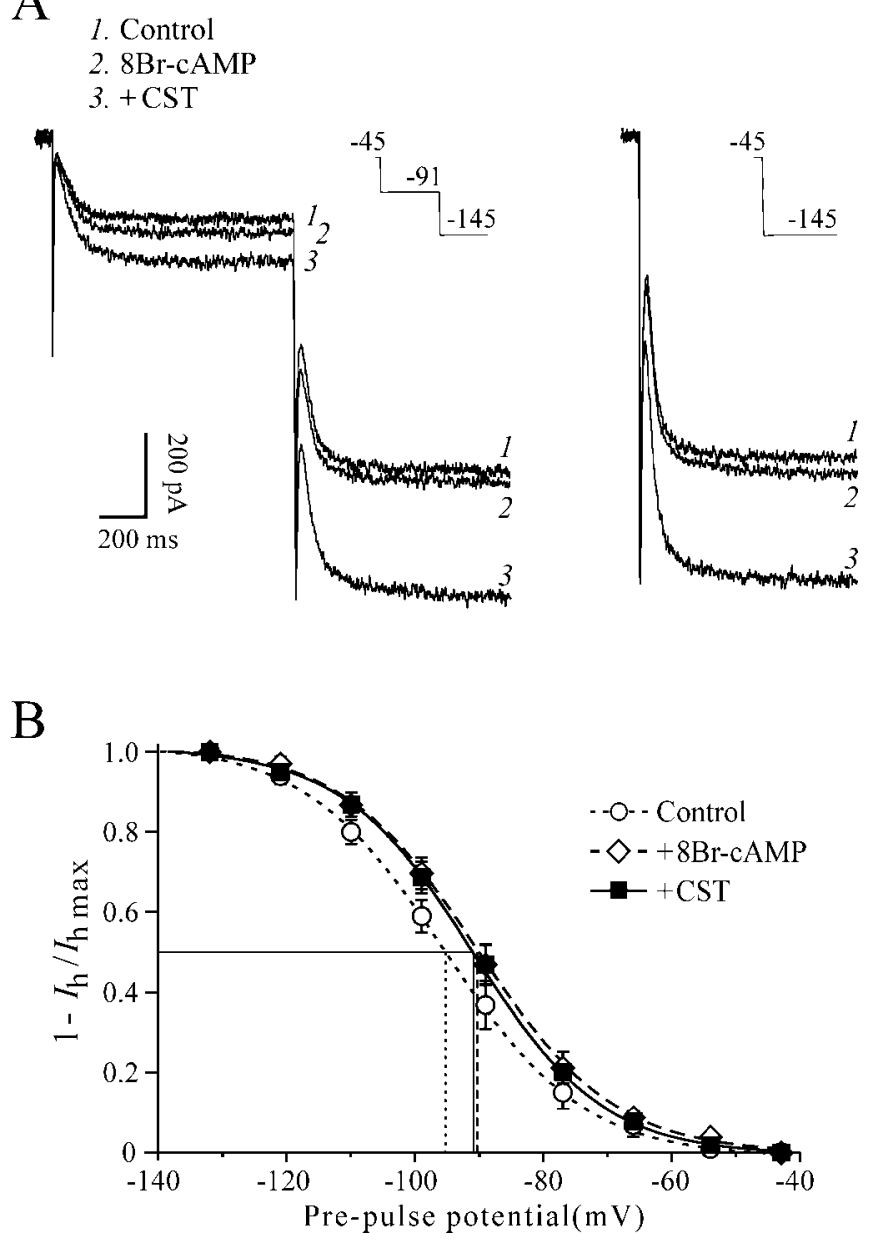

Figure 8. CST augments $I_{h}$ independently of CAMP. $A$, Left, Current recordings from a neuron held at $-45 \mathrm{mV}$ and sequentially stepped to $-91 \mathrm{mV}\left(/_{\mathrm{h}}\right.$ mid-activation) and $-144 \mathrm{mV}$ (full activation). Application of $1 \mathrm{~mm} 8 \mathrm{Br}$-cAMP increased $I_{\mathrm{h}}$ by $13 \%$ at $-91 \mathrm{mV}$ but decreased it by $9 \%$ at $-144 \mathrm{mV}$, suggesting a shift of the activation curve. Additional application of CST in the presence of $8 \mathrm{Br}$-cAMP increased $I_{\mathrm{h}}$ at both potentials (128 and $133 \%$ of $8 \mathrm{Br}$-CAMP values). Right, The same neuron was single stepped from -45 to $-144 \mathrm{mV}$ to fully activate $I_{\mathrm{h}}$ at once. 8Br-cAMP had little effect on $I_{\mathrm{h}}$ (104\% of control), whereas subsequent addition of CST increased $I_{h}$ to $127 \%$ of $8 \mathrm{Br}$-CAMP values. Numbers refer to drug condition; current traces were leak corrected, $1 \mathrm{~mm} \mathrm{Ba}{ }^{2+}$ was used throughout, and RMP was $-68 \mathrm{mV}$ before $\mathrm{Ba}^{2+}$. $B$, Averaged activation curves obtained from six neurons. $8 \mathrm{Br}$-CAMP shifted the activation curve by $+5 \mathrm{mV}$, and subsequent addition of CST did not further affect the curve.

cAMP increased $I_{\mathrm{h}}$ at both prepulse (to $-89 \mathrm{mV}, 128 \pm 3 \%$ of values in $8 \mathrm{Br}$-cAMP) and second step (to $-144 \mathrm{mV}, 129 \pm 3 \%$ ) potentials. Concomitantly, the maximal amplitude of $I_{\mathrm{h}}$ assessed with a single step from -43 to $-144 \mathrm{mV}$ was $130 \pm 3 \%$ of values obtained in 8Br-cAMP alone. The half-activation potential and slope remained unchanged during addition of CST $(-90.8 \pm 1.1$ $\mathrm{mV}$ and $10.1 \pm 0.9$, respectively) (Fig. $8 \mathrm{~B}$ ). Thus, $8 \mathrm{Br}$-cAMP did not alter the effect of CST on $I_{\mathrm{h}}$.

\section{Discussion}

Cortistatin selectively modulates $I_{\mathrm{h}}$

In this study, CST altered membrane currents across the voltage range and occluded the effects of SST. SST is known to augment two sustained conductances in CA1 pyramidal neurons, $I_{M}$ and $I_{\mathrm{K}(\mathrm{L})}$ (Moore et al., 1988; Schweitzer et al., 1998), and CST affected those same $\mathrm{K}^{+}$conductances modulated by SST. Both peptides occluded the effect of each other on these currents, indicating that they act via identical mechanisms. SST and CST 
bind to each of the five cloned SST receptors with similar affinities (Csaba and Dournaud, 2001). The augmentation of $I_{\mathrm{M}}$ and $I_{\mathrm{K}(\mathrm{L})}$ by CST is therefore likely to occur by activation of SST receptors. In locus ceruleus neurons, SST and CST also occlude each other, have similar potencies in augmenting a $\mathrm{K}^{+}$conductance, and are believed to act via SST receptors (Connor et al., 1997).

Our principal finding here is the selective augmentation of the mixed $\mathrm{K}^{+}-\mathrm{Na}^{+}$current $I_{\mathrm{h}}$ by CST, a conductance unaffected by SST. In the presence of SST to activate SST receptors or $1 \mathrm{mM}$ $\mathrm{Ba}^{2+}$ to block the SST-like effects on $I_{\mathrm{M}}$ and $I_{\mathrm{K}(\mathrm{L})}$, CST still elicited an inward steady-state current that had a threshold of activation between -50 and $-55 \mathrm{mV}$ and a mid-activation potential of approximately $-94 \mathrm{mV}$, concomitant with an augmentation of $I_{\mathrm{h}}$ amplitude. The threshold, mid-activation, and saturation potentials, as well as the blockade of the CST-specific effect by ZD 7288, are consistent with the reported properties of $I_{\mathrm{h}}$ in hippocampus (Maccaferri et al., 1993; Gasparini and DiFrancesco, 1997). Because the overall CST response was completely prevented by ZD7288 (to block $I_{\mathrm{h}}$ ) and $\mathrm{Ba}^{2+}$ (to block SST-like effects on $I_{\mathrm{M}}$ and $\left.I_{\mathrm{K}(\mathrm{L})}\right)$, we therefore conclude that CST specifically augments $I_{\mathrm{h}}$.

\section{Cortistatin site of action}

CST and SST have similar affinities for the SST receptors, and none of these receptors preferentially binds CST over SST (Siehler et al., 1998). The CST effect on $I_{\mathrm{h}}$ also occurred in the presence of SST to occupy SST receptors. The selective augmentation of $I_{\mathrm{h}}$ in a concentration-dependent manner by CST, together with its different physiological effects in vivo compared with SST (De Lecea et al., 1996), suggest the existence of a specific receptor. However, the activity of SST receptors can be modified by dimerization or interaction with receptor binding proteins (Rocheville et al., 2000; Csaba and Dournaud, 2001). Thus, CST binding could alter SST receptors and affect their signaling or functional properties in a manner different from SST, leading to a distinct effect on h-channels. Although the existence of a specific CST receptor is enticing, conclusive evidence it still lacking. The $I_{\mathrm{h}}$ density increases from the soma to the dendrites in CA1 pyramidal neurons, and transmitters that affect $I_{\mathrm{h}}$ may alter dendritic excitability preferentially (Magee, 1998; Poolos et al., 2002). Thus, CST could modulate neuronal activity in a cellular compartment unaffected by SST.

The molecular correlates of the h-channels are the HCN genes (Santoro and Tibbs, 1999). The expression of the isoforms HCN1 or HCN1-HCN2 generates channels that activate within a few hundred milliseconds and closely resemble native h-channels seen in CA1 pyramidal neurons (Chen et al., 2001). In our study, CST acted on an $I_{\mathrm{h}}$ component that activated within $300 \mathrm{msec}$, a value comparable with those obtained with coexpression of $\mathrm{HCN} 1-\mathrm{HCN} 2$. However, the limited $5 \mathrm{mV}$ shift of the $I_{\mathrm{h}}$ activation curve elicited by cAMP compares only with values reported with sole expression of HCN1 channels (Chen et al., 2001). The $\mathrm{HCN}$ isoforms that underlie $I_{\mathrm{h}}$ and are targeted by CST in CA1 hippocampus remain to be ascertained.

\section{Mechanism of $I_{\mathrm{h}}$ modulation by cortistatin}

Neuromodulators principally affect $I_{\mathrm{h}}$ by altering cAMP levels to shift the activation curve, rarely by increasing $I_{\mathrm{h}}$ maximal conductance (Pape, 1996). Although activation of SST receptors has been long known to inhibit cAMP production (Csaba and Dournaud, 2001), CST may augment cAMP levels in dissociated hippocampal cells (Sánchez-Alavez et al., 2000). In our hands, 8Br-
cAMP shifted the $I_{\mathrm{h}}$ activation curve by $+5 \mathrm{mV}$ without affecting the maximal conductance. In the presence of $8 \mathrm{Br}$-cAMP, CST still augmented $I_{\mathrm{h}}$ across the voltage range to an extent comparable with that in the absence of $8 \mathrm{Br}$-cAMP. We conclude that cAMP is not involved in the CST effect, which occurs solely via augmentation of $I_{\mathrm{h}}$ maximal conductance.

In hippocampus, muscarinic receptor agonists and gabapentin augment $I_{\mathrm{h}}$ by increasing its maximal conductance independently of cAMP (Colino and Halliwell, 1993; Fisahn et al., 2002; Surges et al., 2003), and serotonin augments $I_{\mathrm{h}}$ by affecting its maximal conductance and activation curve (Gasparini and DiFrancesco, 1999; Bickmeyer et al., 2002). Thus, neurotransmitters that modulate $I_{\mathrm{h}}$ in hippocampal neurons principally augment its maximal conductance, without involvement of cAMP. Such a feature correlates with the high expression in CA1 pyramidal neurons of the HCN1 isoform that is relatively insensitive to cAMP modulation (Franz et al., 2000; Chen et al., 2001). In a recent study performed on brainstem neurons, a $\kappa$-opioid receptor agonist was shown to augment the maximum conductance of $I_{\mathrm{h}}$ via mobilization of intracellular calcium, without shifting the $I_{\mathrm{h}}$ activation curve (Pan, 2003). Such calcium mediation has been proposed in the muscarinic-elicited augmentation of $I_{\mathrm{h}}$ in CA1 hippocampus (Colino and Halliwell, 1993). The modulation of intracellular calcium levels is therefore a possible mechanism underlying the CST augmentation of $I_{\mathrm{h}}$.

\section{Physiological significance}

CST has sleep-modulating properties (De Lecea et al., 1996). Different sleep patterns are shaped by oscillatory activities that emerge from interactions between synaptic activities and intrinsic neuronal properties (Steriade, 2001). Ionic currents that actively oppose changes in membrane voltage and activate slowly regulate the neuronal electrical resonance and interact with network mechanisms of oscillation to modulate brain rhythms (Hutcheon and Yarom, 2000). In hippocampus, $I_{\mathrm{h}}$ affects various oscillatory frequencies (Fisahn et al., 2002; Hu et al., 2002) and has a pivotal role in modulating the integrative properties of neurons and regulating network activity (Magee, 2000). A selective action of CST on $I_{\mathrm{h}}$ gives this peptide a distinctive influence on intrinsic neuronal properties and synaptic integrative mechanisms, thus affecting multiple levels to shape oscillatory activity and brain rhythms.

CST is mostly expressed in cortex and hippocampus and enhances slow-wave sleep (De Lecea et al., 1996). The hippocampus probably is not involved in the control of sleep behavior but is believed to consolidate memory traces and transfer the information to the neocortex during slow-wave sleep (Hobson and PaceSchott, 2002; Sirota et al., 2003). Thus, CST may play a role in memory consolidation by participating in the synchronization of hippocampal and cortical networks during slow-wave sleep. Neocortical and CA1 pyramidal neurons present similar intrinsic properties (Migliore and Shepherd, 2002), and an equivalent effect of CST on the neocortical $I_{\mathrm{h}}$ may be anticipated. Because neocortical neurons control the synchronization of thalamic oscillations during slow-wave sleep (Steriade, 2001), a modulation of $I_{\mathrm{h}}$ by CST in neocortex could have a direct influence on sleep behavior. Another potential effect of CST is to reduce neuronal activity. Although the augmentation of $I_{\mathrm{h}}$ has a depolarizing influence on neuronal membranes, the concomitant attenuation of the temporal summation of excitatory dendritic inputs actually reduces the overall excitability of pyramidal neurons (Magee, 1998; Poolos et al., 2002). The selective augmentation of $I_{\mathrm{h}}$ by CST may therefore oppose excitatory influences on neuronal net- 
works that modulate sleep, such as the excitatory effects of acetylcholine that are blocked by CST but increased by SST (De Lecea et al., 1996).

In our experimental conditions, CST was inhibitory at resting membrane potential and did not generate membrane oscillations because of the preponderance of the SST-like effects. Nonetheless, we anticipate that, in vivo, CST could solely affect $I_{\mathrm{h}}$ because of higher affinity or unique spatial distribution of its putative receptor or signaling system. The selective augmentation of $I_{\mathrm{h}}$ by CST provides a cellular mechanism for its postulated role on sleep distinct from SST. Thus, CST targets a specific site of action that shapes network oscillations and synchronous activity in brain.

\section{References}

Bickmeyer U, Heine M, Manzke T, Richter DW (2002) Differential modulation of $I_{\mathrm{h}}$ by 5 -HT receptors in mouse CA1 hippocampal neurons. Eur J Neurosci 16:209-218.

BoSmith RE, Briggs I, Sturgess NC (1993) Inhibitory actions of ZENECA ZD7288 on whole-cell hyperpolarization activated inward current (If) in guinea-pig dissociated sinoatrial node cells. Br J Pharmacol 110:343-349.

Braun H, Schulz S, Becker A, Schröder H, Höllt V (1998) Protective effects of cortistatin (CST-14) against kainate-induced neurotoxicity in rat brain. Brain Res 803:54-60.

Brown DA, Gähwiler BH, Griffith WH, Halliwell JV (1990) Membrane currents in hippocampal neurons. Prog Brain Res 83:141-160.

Chen C, Wang C, Siegelbaum SA (2001) Properties of hyperpolarizationactivated pacemaker current defined by coassembly of HCN1 and HCN2 subunits and basal modulation by cyclic nucleotide. J Gen Physiol 117:491-503.

Colino A, Halliwell JV (1993) Carbachol potentiates Q current and activates a calcium-dependent non-specific conductance in rat hippocampus in vitro. Eur J Neurosci 5:1198-1209.

Connor M, Ingram SL, Christie MJ (1997) Cortistatin increase of a potassium conductance in rat locus coeruleus in vitro. $\mathrm{Br} \mathrm{J}$ Pharmacol 122:1567-1572.

Csaba Z, Dournaud P (2001) Cellular biology of somatostatin receptors. Neuropeptides 35:1-23.

De Lecea L, Criado JR, Prospéro-García O, Gautvik KM, Schweitzer P, Danielson PE, Dunlop CLM, Siggins GR, Henriksen SJ, Sutcliffe JG (1996) A cortical neuropeptide with neuronal depressant and sleepmodulating properties. Nature 381:242-245.

De Lecea L, Del Rio JA, Criado JR, Alcántara S, Morales M, Danielson PE, Henriksen SJ, Soriano E, Sutcliffe JG (1997) Cortistatin is expressed in a distinct subset of cortical interneurons. J Neurosci 17:5868-5880.

Fisahn A, Yamada M, Duttaroy A, Gan JW, Deng CX, McBain CJ, Wess J (2002) Muscarinic induction of hippocampal gamma oscillations requires coupling of the M1 receptor to two mixed cation currents. Neuron 33:615-624.

Franz O, Liss B, Neu A, Roeper J (2000) Single-cell mRNA expression of HCN1 correlates with a fast gating phenotype of hyperpolarizationactivated cyclic nucleotide-gated ion channels (Ih) in central neurons. Eur J Neurosci 12:2685-2693.

Gasparini S, DiFrancesco D (1997) Action of the hyperpolarizationactivated current (Ih) blocker ZD 7288 in hippocampal CA1 neurons. Pflügers Arch 435:99-106.

Gasparini S, DiFrancesco D (1999) Action of serotonin on the hyperpolarization-activated cation current $\left(I_{h}\right)$ in rat CA1 hippocampal neurons. Eur J Neurosci 11:3093-3100.

Halliwell JV, Adams PR (1982) Voltage-clamp analysis of muscarinic excitation in hippocampal neurons. Brain Res 250:71-92.

Hobson JA, Pace-Schott EF (2002) The cognitive neuroscience of sleep: neuronal systems, consciousness and learning. Nat Rev Neurosci 3:679-693.

$\mathrm{Hu}$ H, Vervaeke K, Storm JF (2002) Two forms of electrical resonance at theta frequencies, generated by M-current, h-current and persistent $\mathrm{Na}^{+}$ current in rat hippocampal pyramidal cells. J Physiol (Lond) 545:783-805.

Hutcheon B, Yarom Y (2000) Resonance, oscillation and the intrinsic frequency preferences of neurons. Trends Neurosci 23:216-222.

Johnston D, Brown TH (1983) Interpretation of voltage-clamp measurements in hippocampal neurons. J Neurophysiol 50:464-486.

Luthi A, McCormick DA (1998) H-current: properties of a neuronal and network pacemaker. Neuron 21:9-12.

Maccaferri G, Mangoni M, Lazzari A, DiFrancesco D (1993) Properties of the hyperpolarization-activated current in rat hippocampal CA1 pyramidal cells. J Neurophysiol 69:2129-2136.

Magee JC (1998) Dendritic hyperpolarization-activated currents modify the integrative properties of hippocampal CA1 pyramidal neurons. J Neurosci 18:7613-7624.

Magee JC (2000) Dendritic integration of excitatory synaptic input. Nat Rev Neurosci 1:181-190.

Migliore M, Shepherd GM (2002) Emerging rules for the distributions of active dendritic conductances. Nat Rev Neurosci 3:362-370.

Moore SD, Madamba SG, Joëls M, Siggins GR (1988) Somatostatin augments the M-current in hippocampal neurons. Science 239:278-280.

Pan ZZ (2003) kappa-opioid receptor-mediated enhancement of the hyperpolarization-activated current $\left(I_{\mathrm{h}}\right)$ through mobilization of intracellular calcium in rat nucleus raphe magnus. J Physiol (Lond) 548:765-775.

Pape HC (1996) Queer current and pacemaker: the hyperpolarizationactivated cation current in neurons. Annu Rev Physiol 58:299-327.

Poolos NP, Migliore M, Johnston D (2002) Pharmacological upregulation of h-channels reduces the excitability of pyramidal neuron dendrites. Nat Neurosci 5:767-774.

Rocheville M, Lange DC, Kumar U, Patel SC, Patel RC, Patel YC (2000) Receptors for dopamine and somatostatin: Formation of heterooligomers with enhanced functional activity. Science 288:154-157.

Sánchez-Alavez M, Gómez-Chavarín M, Navarro L, Jiménez-Anguiano A, Murillo-Rodríguez E, Prado-Alcalá RA, Drucker-Colin R, ProspéroGarcía O (2000) Cortistatin modulates memory processes in rats. Brain Res 858:78-83.

Santoro B, Tibbs GR (1999) The HCN gene family: molecular basis of the hyperpolarization-activated pacemaker channels. Ann NY Acad Sci 868:741-764

Schweitzer P, Madamba SG, Champagnat J, Siggins GR (1993) Somatostatin inhibition of hippocampal CA1 pyramidal neurons: Mediation by arachidonic acid and its metabolites. J Neurosci 13:2033-2049.

Schweitzer P, Madamba SG, Siggins GR (1998) Somatostatin increases a voltage-insensitive $\mathrm{K}^{+}$conductance in rat CA1 hippocampal neurons. J Neurophysiol 79:1230-1238.

Siehler S, Seuwen K, Hoyer D (1998) $\left[{ }^{125} \mathrm{I}\right] \mathrm{Tyr}^{10}{ }^{\text {-cortistatin }}{ }_{14}$ labels all five somatostatin receptors. Naunyn Schmiedebergs Arch Pharmacol 357:483-489.

Sirota A, Csicsvari J, Buhl DL, Buzsáki G (2003) Communication between neocortex and hippocampus during sleep in rodents. Proc Natl Acad Sci USA 100:2065-2069.

Steriade M (2001) Impact of network activities on neuronal properties in corticothalamic systems. J Neurophysiol 86:1-39.

Surges R, Freiman TM, Feuerstein TJ (2003) Gabapentin increases the hyperpolarization-activated cation current $\mathrm{I}_{\mathrm{h}}$ in rat CA1 pyramidal cells. Epilepsia 44:150-156.

Vasilaki A, Lanneau C, Dournaud P, De Lecea L, Gardette R, Epelbaum J (1998) Cortistatin affects glutamate sensitivity in mouse hypothalamic neurons through activation of sst 2 somatostatin receptor subtype. Neuroscience $88: 359-364$ 